\title{
Fluency and Aphasia: A pragmatic reconsideration
}

\author{
Claire Penn PhD (Witwatersrand)
Department of Speech Pathology and Audioh \\ University of the Witwatersand
}

ABSTRACT The fluency behaviour of fourteen aphasic patients was investigated within a communicative framework. As part of an overall
pragmatic analysis, judges were required to rate the subjects' fluency behaviour as to their appropriateness within the context
of interactive discourse. Results indicated differences between subjects which related consistently neither to
type of aphasia nor to severity. Implications regarding the characteristifis.
are discussed. are discussed.

\section{OPSOMMING} Implikasies aangaande die karakterisering vaie verskille nie met beide die tipe- of graad van afasie is gevind dat daar ver. vlotheid en die nut hiervan vir klassifikasie word bespreek. expressive output is a feature which of fluency in aphasic frequently in the literature. In which has been commented on pressive output which has formed the is this dimension of exof classificatory schemes in armed the basis of a large number for example, that at least $75 \%$ of the Wagenaar et al ${ }^{16}$ claim, can be distinguished along the of the entire aphasic population a differentiation is made bet fluency dimension. Essentially, agrammatic) patient, whose speech "nonfluent" (anterior, or halting and effortful with peech production is typically mistakes, short utterances, poor prosody, pronunciation of function words ances, grammatical errors and omission presents with fluent, rapid so-called "fluent" aphasic who effortless sentences rapid speech with normal prosody, long grammar.

It is clear from the above definitions that such cla schemes incorporate not only prosodic that such classificatory ticulation and syntax into their definitio features but also artional definitions of fluency are, howitions of fluency. TradiMost, for example, emphasise however, less encompassing. aspects of speech and include the temporal and sequential tions, repetitions and interruptions. ${ }^{5}$ such as pauses, hesitative is derived from the context of langun alternative perspecverence to the rules of the languaguage usage and includes vocabulary and competence in disuage, the use of appropriate Clearly, in aphasia, we are in discourse

fluency, though traditionally, concerned with both aspects of ed themselves more with tempeech therapists have concernfluency. Recently the effect of lingul and sequential aspects of fluency behaviour has of linguistic content and context on Die Suid-Afrikaanse Tjustifired attention. There is considerable evidence to suggest for example, that normal speech the distribution, frequency discontinuous activity"s and that heavily on the semantic and cognitive hesitations depends message and on the nature of the content of the verbal interaction.

As such, it is clear that as Dalton and Hardcastles suggest, fluency is a very sensitive indicator of the overall potency of should be perceived theref. The fluency disruption in aphasia type and locus of brain damage, an indicator not only of the of communicative competence.

Limited evidence for thr

comparing aphasic and norme statement comes from studies an investigation of fluency disuency disturbances and from children. In a study by Yairi et al is in language-impaired taneous speech of Broca's aphasics with comparing the sponcontrols, though the frequency with that of age-matched aphasics' speech was three times of dysfluencies in the trol group, the nature of these dysfluter than that of the connormal patterns. The fact that onlyencies strongly resembled in this study and that the data base fora's patients were used phrases rather than spontaneous for analysis was elicited sions which may be made with regard to limits the conclution as a whole. However, the implict to the aphasic populafluency of aphasics may be sensitive to this study is that communicative event, not to brain to components of the Brown and Cullinan ${ }^{2}$ comment to brain damage alone. Similarly tween dysfluent speech and on the close relationship be(c) SASHA 1983 
is the concept of nonfluency as opposed to dysfluency, the former referring to a disruption in copiousness of verbal output, the latter to a disruption of speech flow. In discourse, the presence of fluency problems has been shown to interfere with overall cohesion. In a study investigating the spontaneous discourse of a group of language-impaired children, fluency (or lack thereof) was found to be a feature of discourse significantly differentiating their overall cohesion in relation to that of matched normals. ${ }^{1}$

It thus seems pertinent for the language pathologist to examine fluency from a slightly different perspective than usual, i.e. as a feature of speech behaviour potentially capable of interfering with the basic communicative effectiveness of the message. In other words, it can be argued that fluency is a pragmatic phenomenon - one which is influenced by the context of the communicative event.

The above points provided the rationale for the inclusion of the fluency dimension as part of an investigation of broader pragmatic capabilities in a group of aphasic patients.* The specific methodology and results of the fluency analysis will now be described.

\section{METHOD}

In an attempt to investigate the relative importance of fluency in the overall assessment of communicative appropriateness, a scale was devised to reflect pragmatic competence in fluency terms. The purpose of this analysis was to examine the nature of the relationship between results on the fluency scale and type and severity of aphasia as measured on a traditional struc- tured measure of aphasia - the Boston Diagnostic Aphasia Examination (BDAE). 9

\section{SUBJECTS (Ss)}

Fourteen English-speaking adult aphasic patients were selected for the study according to certain criteria. These included confirmed presence of aphasia, neurological stability and the absence of gross concomitant problems. Etiology of aphasia was not held constant in the group; neither were classification or severity of aphasia (as measured on the BDAE). Table 1 illustrates relevant case history information pertaining to the subjects.

\section{TESTING}

The data base for analysis was a twenty-minute videotaped language sample. The sample for each $S$ was recorded in the context of a conversation with a familiar speech therapist. Each interactive language sample was divided into twenty oneminute 'chunks' which served as the units for analysis. Two trained judges (speech pathology graduates) were required to rate the fluency behaviours during each conversational unit for each patient, along the dimensions presented in Table 2 .

The categories selected to describe the fluency behaviours of the Ss are those suggested by Yairi and Clifton ${ }^{17}$ who examined fluency breakdown in three groups of normal speakers. In addition, the categories of 'false start' and 'word-finding difficulty' were included, as both aspects were felt to be characteristic of aphasic language ${ }^{3}$ and both cause fluency disruption.

The judges were required to characterise the overall ap-

Table 1 Case history details pertaining to subjects used in the study

\begin{tabular}{|c|c|c|c|c|c|}
\hline SUBJECT & AGE & SEX & $\begin{array}{l}\text { BDAE } \\
\text { CLASSIFICATION }\end{array}$ & $\begin{array}{c}\text { BDAE } \\
\text { SEVERITY RATING }\end{array}$ & $\begin{array}{l}\text { BEHAVIOURAL } \\
\text { CLASSIFICATION }\end{array}$ \\
\hline $\begin{array}{r}1 \\
2 \\
3 \\
4 \\
5 \\
6 \\
7 \\
8 \\
9 \\
10 \\
11 \\
12 \\
13 \\
14\end{array}$ & $\begin{array}{l}53 \\
50 \\
50 \\
63 \\
58 \\
24 \\
61 \\
63 \\
53 \\
59 \\
36 \\
63 \\
41 \\
72\end{array}$ & $\begin{array}{l}\mathbf{F} \\
\mathbf{F} \\
\mathbf{M} \\
\mathbf{F} \\
\mathbf{M} \\
\mathbf{M} \\
\mathbf{M} \\
\mathbf{M} \\
\mathbf{M} \\
\mathbf{M} \\
\mathbf{F} \\
\mathbf{F} \\
\mathbf{M} \\
\mathbf{F}\end{array}$ & $\begin{array}{l}\text { Anomic } \\
\text { Broca's } \\
\text { Conduction } \\
\text { Broca's } \\
\text { Global - Broca's } \\
\text { Global - Wernicke's } \\
\text { ? Broca's } \\
\text { Wernicke's } \\
\text { Aphemic } \\
\text { ? Broca's } \\
\text { Broca's } \\
\text { Wemicke's } \\
\text { Anomic } \\
\text { Wernicke's }\end{array}$ & $\begin{array}{l}3-4 \\
2 \\
3 \\
1 \\
1 \\
1 \\
2 \\
2 \\
4 \\
3 \\
2 \\
3 \\
4 \\
2-3\end{array}$ & $\begin{array}{l}\text { Fluent } \\
\text { Nonfluent } \\
\text { Fluent } \\
\text { Nonfluent } \\
\text { Nonfluent } \\
\text { Mixed } \\
\text { Mixed } \\
\text { Fluent } \\
\text { Mixed } \\
\text { Mixed, } \\
\text { Nonfupent } \\
\text { Fluent' } \\
\text { Fluent } \\
\text { Fluent' }\end{array}$ \\
\hline
\end{tabular}

Table 2 Fluency Rating Scale Explanation: This measure entails judging the appropriateness of the patient's fluency control within each Conversational Unit
(C.U.) of one minute.

\begin{tabular}{|c|c|c|c|}
\hline BEHAVIOURS CONSIDERED & $\begin{array}{l}\text { EXPLANATION AND/OR } \\
\text { EXAMPLES }\end{array}$ & $\begin{array}{l}\text { EXAMPLES OF APPROPRIATE } \\
\text { USE IN CONTEXT }\end{array}$ & $\begin{array}{l}\text { EXAMPLES OF INAPPROPRIATE } \\
\text { USE IN CONTEXT }\end{array}$ \\
\hline $\begin{array}{l}\text { Interjections } \\
\text { Repetitions } \\
\text { Revisions } \\
\text { Incomplete phrases } \\
\text { False Starts } \\
\text { Pauses } \\
\text { Word-finding difficulties }\end{array}$ & $\begin{array}{l}\text { Items traditionally associated } \\
\text { with a measurement of non- } \\
\text { fluency, viz. aspects which break } \\
\text { the normal flow of speech }\end{array}$ & $\begin{array}{l}\text { Normal acceptable non-fluencies } \\
\text { which do not interfere with } \\
\text { listener's understanding of } \\
\text { message }\end{array}$ & $\begin{array}{l}\text { Non-fluencies which interfere } \\
\text { with coherence, timing or } \\
\text { sequence of the message. } \\
\text { Inappropriate interference in transition } \\
\text { smoothness between segments }\end{array}$ \\
\hline
\end{tabular}

" This paper is based on a section of the writer's PhD thesis, entitled "Syntactic and Pragmatic Aspects of Aphasic Language". 
propriateness of each subject's fluency behaviour in each conversational unit on a five-point rating scale with the following
format:

\begin{tabular}{|c|c|c|c|c|}
\hline $\begin{array}{l}\text { The patient's } \\
\text { control of } \\
\text { fluency was } \\
\text { not ap- } \\
\text { propriate } \\
\text { within this } \\
\text { conversa- } \\
\text { tional unit }\end{array}$ & $\begin{array}{l}\text { The patient's } \\
\text { control of } \\
\text { fluency was } \\
\text { mostly inap- } \\
\text { propriate } \\
\text { within this } \\
\text { conversa- } \\
\text { tional unit }\end{array}$ & $\begin{array}{l}\text { It is difficult } \\
\text { to decide } \\
\text { whether the } \\
\text { patient's } \\
\text { control of } \\
\text { fluency was } \\
\text { appropriate } \\
\text { or not for } \\
\text { this con- } \\
\text { versational } \\
\text { unit }\end{array}$ & $\begin{array}{l}\text { The patient's } \\
\text { control of } \\
\text { fluency was } \\
\text { mostly ap- } \\
\text { propriate } \\
\text { within this } \\
\text { conversa- } \\
\text { tional unit }\end{array}$ & $\begin{array}{l}\text { The patient's } \\
\text { control of } \\
\text { fluency was } \\
\text { appropriate } \\
\text { within this } \\
\text { conversational } \\
\text { unit }\end{array}$ \\
\hline
\end{tabular}

This format was selected on the basis of the results of a pilot study. The key notion underlying the above scale is that of "appropriateness" - a term which has been used increasingly in the aphasic's ability to language. With a burgeoning focus on idea reflected for instommunicate rather than speak - an - the judgment of a patient's the recent work of Holland ${ }^{10.11}$ (rather than correct) within behaviour as being appropriate considerable clinical atration communicative context has

Judges' ratings were supplemented for each subject by written justification for the decisions made. These qualitative comments were used in analysis of the data as a supplement to the main technique.

\section{DATA ANALYSIS}

The approach to data analysis was essentially taxonomic utilising the method of hierarchical cluster analysis. This is a computerised mathematico-deductive procedure particularly suitable for the analysis of multivariate data. It enables the obsimilarities, whil of individuals on the basis of their and interpretive element same time allowing for the deductive research. Aside from which is so necessary in linguistic workers, ${ }^{12}$ the appliom the work of Kertesz and his codate been limited cluster analysis to aphasia has to of neuropsychology benefits of this method in related areas The BMDP programme however been well documented. ${ }^{14}$ study. ${ }^{7}$ Once interthe judges (using-rater reliability had been established for means for each Cohen's weighted Kappa formula, ${ }^{4}$ ) the analysis.

\section{RESULTS}

From the variety of techniques available for clustering sets of suitable for the that the techniques which would be most linkage diagram present investigation were the derivation of a field. Figures 1, 2 and 3 rogram and its counterpart, the cluster the dendrogram and 3 represent the linkage (tree) diagram, analysis of fluency rating. cluster field respectively for the ing of $\mathrm{Ss}$ is indicy ratings. In the linkage diagram, the groupline above a particul by the means of the intersection of the the $S$. The strength $S$ and the diagonal line starting next to numerical valuesth of the association is represented by to 100 and represent the tree. These values are scaled from 1 Die Suid-Afrikaanse higher the association between Ss in terms of their fluency generated cluster tree value in the tree. From the computerderived, representing in a degram and cluster field may be ship between Ss. Those $S$ sictographic manner, the relationreported in terms of similar to each other are in the cluster field similar, with decreasing similarity circles are judged most larger circles.

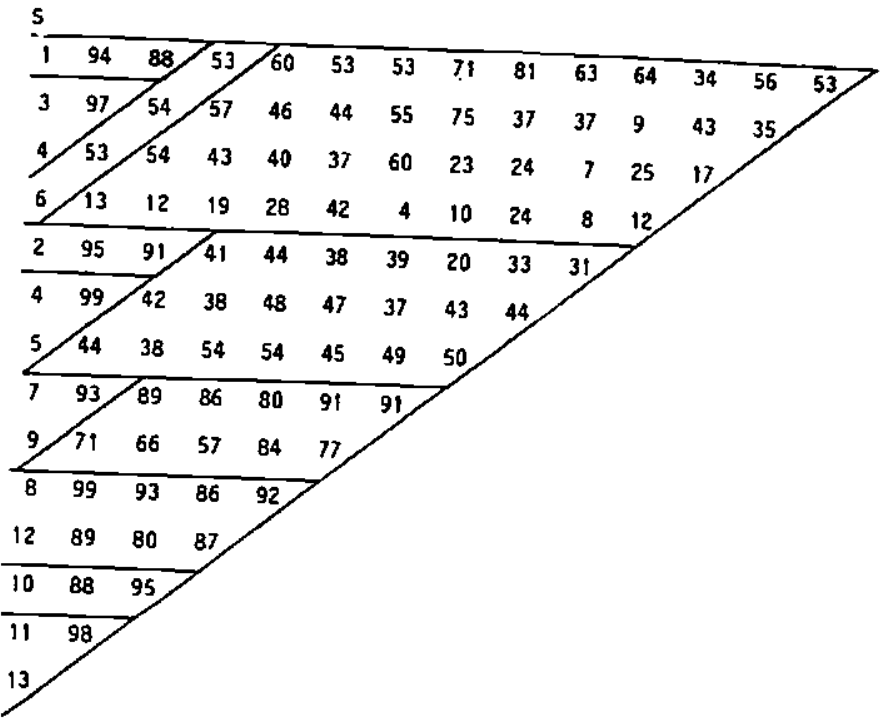

Figure 1 Linkage tree demonstrating degree of similarity between subjects on Fluency Scale

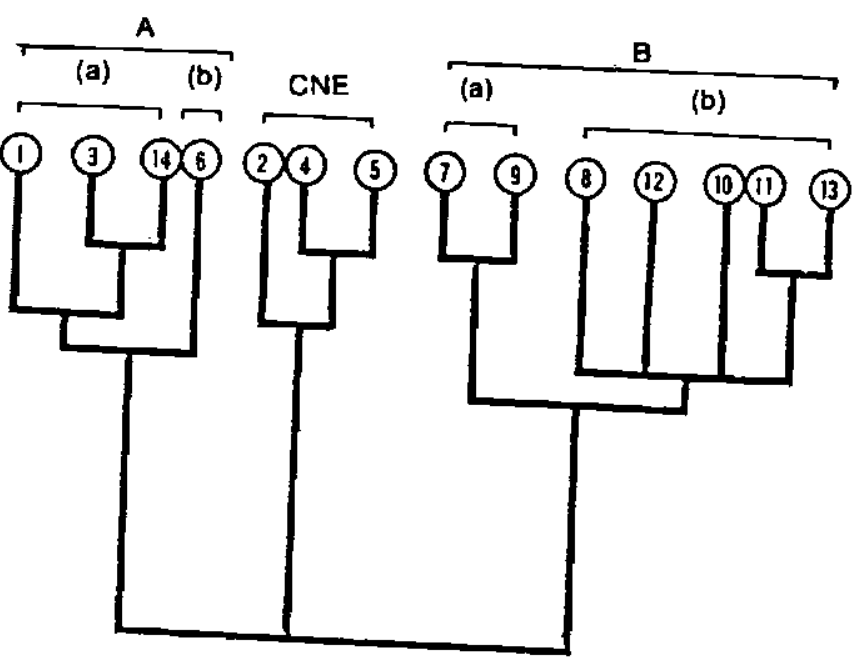
Figure 2 Dendrogram demonstrating degree of similarity
between subjects on Fluency Scale

As Figures 1 and 2 suggest, two main groups of Ss were identified by the cluster analysis on the Fluency Scale. The first group (three $\mathrm{Ss}$ ) was generally rated by the judges to show appropriately fluent behaviour whereas the second group was considered by the judges to have fluency behaviours often inings were recognised communicative flow. Many subgroup$6,2,8,12$ and 10 ) by the cluster analysis and several Ss (I, distinctions will be colatively distinct patterns. These distinctions will be considered under each broad group.

\section{A. APPROPRIATE GROUP}

All three Ss in this group (1, 3, 14 - Group A(a)) could be diagnosed as being 'fluent' in traditional terms. Nevertheless

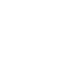


instances of the nonfluent behaviours identified by Table 2 occurred predictably in all Ss. SI4 showed considerably fewer of these behaviours than other Ss in this group. In fact, both judges commented on her behaviours as being 'too fluent'. In many conversational turns there were no examples of nonfluencies at the expected junctures. This could perhaps be tied to a self-monitoring defect, which will be discussed later. This is illustrated by:

S14 T: So you're doing a lot of work at home?

P: Well I must. It's the only way. First of all it's easier for me to learn things as I do. ( ) *When they speak to me I ask them. It's a lovely feeling. It really is. It's difficult but it slowly slowly come right. Writing nicely. My writing's very well. It improved a lot I think so it makes a I feel so good then I start again then it's lovely.

S3 showed, by contrast to S14, instances of revision, repetition and hesitation which, though judged as largely appropriate, were sometimes seen as interfering with communicative flow. This aspect was also noted in S1's sample. Her frequent use of 'er' and occasional word-finding difficulty were felt to interfere with the flow of the message though overall fluency was maintained through the discourse. e.g.'s:

S3 T: You want to go and see the top man?

P: Right right. So um about um He'll give us a letter an answer you see. About a month later had a chat this fellow on the telephone. 'Look what do you think?' He says no I'm sorry we can't do it but I'll send us a letter. He will send us a letter which is three months later.

(Note revision or "high level amendment" to use Butterworth's ${ }^{3}$ term.)

Sl P: My son is in er Escom but er it's in Germiston and er he has to er by six o'clock he must er he goes by car but actually he goes afterwards by er train. it's easier you know because er er not so expensive to go by car.

S6 (A(b)) warrants special comment. His tie with the other Ss in this group was low $(0,53)$. All aspects of nonfluency were observed by the judges to occur very frequently. This S's rapid rate of speech, however, provides the listener with an overall impression of fluency. Thus judgments of inappropriate were in part offset by this factor. e.g.:

S6 T: So you hit your hand?

P: Ja Ja Ja Ag you know Lovey. Um you see this one. This look now what $(\quad)$

T: The drink

P: You see how look but if you ( ) like this one I'll never you'll do the same lovey. I never said you know I promise you I had enough.

\section{B. INAPPROPRIATE}

The severely restricted output of Ss 2, 4 and 5 made judgments of fluency difficult in terms of the categories suggested on the fluency scale (Table 2). Thus these Ss are grouped together in the cluster analysis, the few possible opportunities for judgment indicating that repetitions, false starts and incomplete phrases hindered overall communicative flow. e.g.:

S2 T: Why did they have collars round their necks?

P: They had something ( )

* Unintelligible utterance.
Claire Penn

T: Oh so they had something done to them?

$P$ : No one the man who the man who was ( ) The manner of speaking in Ss 7 and 9 (B(a)) also seemed to account for judgments of their fluency being very similar. Both of these Ss have a particularly slow rate of speech resulting in lengthy unfilled pauses. Other aspects of nonfluency in these Ss (e.g. interjection and repetitions) were felt to be appropriate and not a hindrance to communicative flow. e.g.:

S7 T: Don't your grandchildren go to school?

P: No they - they a small. They too small yet. They er er the er oldest one he does to s - - kindergarten you know and er the other one he can't walk yet.

S9 T: Do you prefer some programmes to others on TV?

P: No. Er - - er - - Sport - 1 like and er - - um er progra and - - er - - a few programmes a week.

The remaining five $S s(B(b))$ were all judged to have many instances of inappropriate fluency behaviours in their samples (despite the fact that three of this group could be traditionally classified as 'fluent' $\mathrm{Ss}$ ). All behaviours delineated by the Scale were noted in all Ss but the following were commonly felt to interfere specifically with communicative flow: interjections and repetitions (in four out of five Ss), pauses and word-finding difficulties (in all five Ss) and incomplete phrases and false starts (in three Ss). It appeared that the longer the conversational turn on the part of the $S$ and the higher the frequency of non-fluent behaviours in such a turn, the more likely it was that the $S$ would be judged as being inappropriate with regard to fluency. This was particularly noticeable for $\mathrm{S12}$ :

T: She lives here?

P: No in er near Durban. They've got a farm and er I feel there's something funny so I phoned her and er she said. Well she er I'm fine Honey am um I'm not so well but I'm fine but er did you get my letter? So I said No. Anyway um so I waited for the letter and er then the letter that worried me so much because she told me that um that I had flu.

Broca's patients, Ss 10 and 11 had relatively impaired syntactic output in relation to other $S s$ in this group and their nonfluencies e.g. repetitions, revisions and interjections were felt in part to be not altogether successful attempts to compensate for this, e.g.:

S10 T: How would you change a tyre?

P: Well I don't to I would put er a a jack and then I would - put a - wheel up a little bit and then I would get the bolts er in the not in the bolts and - put it in under the - See?

SIl T: What did you do?

P: Um Talk. Hospital Um Um Um. Two time a week.

T: You go there for therapy?

P: Yes Um um um yes - um my hand, my leg.

Word-finding behaviours seemed to affect fluency judgments of Ss 8 and 13. e.g.s:

S8 T: Could you tell me how to change a tyre?

P: Yes well I I I know what it is. Obviously and went on - . but it's hard hard to get something.

T: What do you do?

P: You know it's difficult - - Um - you know I told all forever in ( ) things like that. Beautiful well unfor- 
tunately as it went down down and so I was getting useless. But how do I do it?

S13 P: It's a sort of thing you wind up and a thing you get to play records not records but it's a records record sounds like a records something.

T: A tape rcorder?

P: No no no not a tape recorder. Um - -

T: Not a record player?

$P$ : No no no not a record. Not strictly a record player. It's for infants of the age 2 to 6 .

T: Is it one of those Fisher Price toys?

P: Fisher Price. Fisher Price. Yes. Fisher Price.

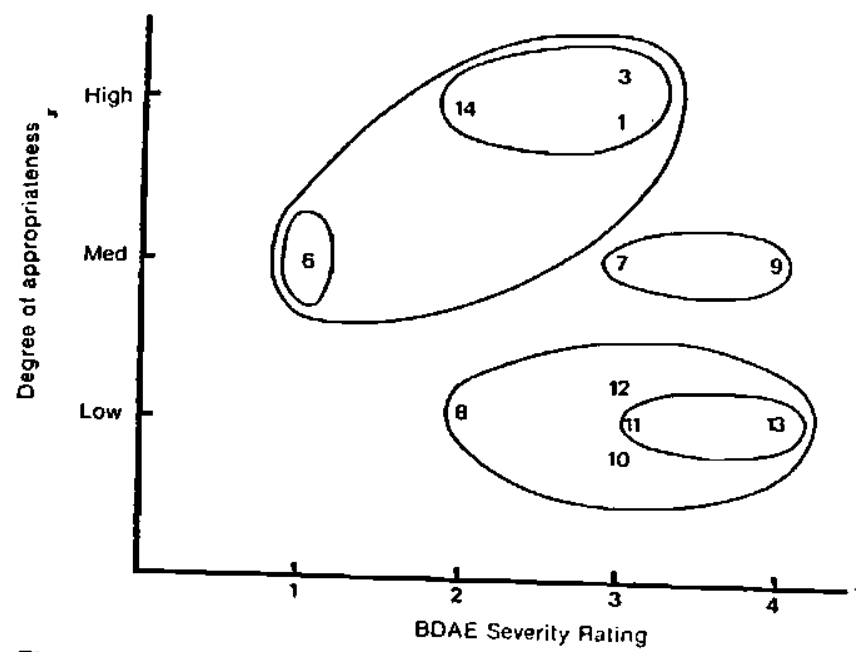

Figure 3 Clustering of the subjects on Fluency Scale in relation to Appropriateness and severity ratings

By way of a summary, in Figure 3 the main clusters of patients are plotted against overall degrees of appropriateness and the BDAE severity rating for fluency ratings. For reasons described above, Ss 2, 4 and 5 were not included in this analysis. Of the remaining subjects, three were judged to have overall high levels of appropriate fluency, one showed a somewhat equivocal pattern and three by virtue of their severe agrammatism could not be effectively, judged. Seven Ss were rated as having instances of inappropriate fluency either related to manner of production, length of turn or word-finding difficulties. Clusters suggest more cases of inappropriate nonfluency in the group of Ss as a whiole than appropriate nonfluency and further that aphasia type does not necessarily correlate with judgments of appropriateness. Clear-cut distinctions were not found on this scale either with regard to appropriateness or severity.

\section{DISCUSSION}

The results obtained confirm to a large extent recent published findings with regard to the fluency disorder in aphasia, viz:

- that aphasics show many instances of dysfluency and that these dysfluencies are greatly influenced by word position/grammatical function.

- that there is not always a correlation between clinical form of aphasia and type of fluency

- that the measurement and rating of fluency is not a simple
matter

- that the examination of fluency in aphasic speech may offer some insight into the mechanisms of normal speech
production ${ }^{3,6}$

Die Suid-Afrikaanse Tydskrif vir Kommunikasieafwykings, Vol. 30, 1983
With the exception of S 14, all the subjects in the present study demonstrated many instances of dysfluency in their expressive language samples. This confirms a large body of literature which discusses dysfluency phenomena in aphasia. ${ }^{2} .15 .18$ The relative dearth of research into aphasia in relation to normal nonfluencies make such results difficult to interpret.

In spite of this, the present data tends to confirm suggestions of workers such as Butterworth ${ }^{3}$ that the type and locus of dysfluencies in aphasia are similar to those in normals. Though the frequency of such behaviours was not directly measured in the present study it was this aspect which appeared to influence judges' qualitative decisions.

With regard to type of dysfluency observed, judges noted instances of all behaviours delineated on the scale, viz: interjections, repetitions, revisions, incomplete phrases, false starts and word-finding difficulties. These occurred at predictable junctures in terms of the literature on normal dysfluency phenomena, e.g. at syntactic boundaries, before content words and after an error in production. ${ }^{8}$ The fact that most aphasic subjects by definition have greater difficulty in formulating verbal output would lend support to the idea that associated dysfluency would be higher. This is clearly not the case in S14 who conforms to the classic description of jargon aphasia offered by Kinsbourne and Warrington, ${ }^{3}$ viz: "the jargon aphasic speaks in a copious flow uninterrupted by hesitation and correction". Unlike the patient described by Butterworth, ${ }^{3} \mathrm{~S} 14$ showed no instances of hesitation prior to the production of neologisms, nor indeed at expected junctures. This provides some support for the 'disinhibition' explanation advanced for this type of aphasia. Essentially it refers to a lack of self-monitoring such subjects have over their own output. Acknowledging that an analysis of hesitations and associated non-fluencies may provide an indicator of how the speaker monitors his production, the nature of this type of aphasic deficit is thus apparent.

It became clear during the rating of this scale that the assessment of fluency, particularly with regard to appropriateness, is a very complex matter. Judges' verbal and written justifications were often not specifically related to the frequency, locus or type of dysfluency per se but on the overall impression gained. A measurement of fluency control inter alia involves aspects such as number of words, speaking time and speaking rate (which in themselves comprise variables such as phonation rate, number and duration of silent pauses). ${ }^{6}$ The present study did not include rate as part of the fluency scale (cf. Yairi et al.). ${ }^{18}$ Rather this was seen as a paralinguistic behaviour to be measured on another scale. Similarly, hesitation analysis was subsumed broadly under 'pauses'. In the sense that global rather than quantitative decisions were required in the present study, this somewhat restricted taxonomy of fluency aspects is acceptable. It does, however, suggest that ratings may have been made on the basis of behaviours other than those delineated by the scale.

Finally, and of particular relevance, the results on the Fluency Scale showed that there was not always a correlation between the clinical form of aphasia and type of fluency rating. This supports the findings of Deloche et al. ${ }^{6}$ who showed that when certain aspects of fluency are considered, no clearcut differentiations in terms of aphasic types suggest themselves. 
The results of the present study suggest that some dysfluencies actually enhance the communicative process since they reflect underlying linguistic processing on the aphasic's part and apparently shadow normal strategies. In other words they appear to be an indication to the listener that the aphasic is attempting to retrieve the word, is self-monitoring and is employing (however inefficiently) search strategies which reflect communicative motivation. It is only when such behaviours occur with high frequency or at unexpected junctures that they are judged inappropriate. The fact that these behaviours occur in all but one of the subjects studied casts some doubt onto the question of the utility of the fluency/non-fluency dichotomy which has been used to differentiate aphasics. This point will now be expanded.

\section{IMPLICATIONS}

The writer would suggest on the basis of the above results that the dichotomy of "fluent" versus "nonfluent" aphasia is a potentially misleading one.

If this terminological distinction is used to separate patients on the basis of expressive output alone, and if the definitions involved are specified clearly and precisely, then it does have the advantage of reducing terminological confusion. ${ }^{16}$ However, as research on both normal and abnormal speakers suggests, fluency is a very complex phenomenon comprising a number of component parts and is hence difficult to measure. Deloche et al. ${ }^{6}$ point out that traditional aphasic classification schemes often incorporate different aspects into their definitions of fluency.

Even on the fluency scale in this study which incorporates components traditionally associated with an analysis of fluency, clear-cut distinctions in terms of appropriateness could not be consistently made between nonfluent and fluent Ss. Thus many of the so-called 'fluent' Ss were judged to be inappropriate along these dimensions. A problem of definition arises here. The components of the fluency scale are certainly more conventional than the broad definitions applied by aphasiologists and hence may well have been too restricted to derive differences among patients.

Notwithstanding this, the writer would suggest that the terms nonfluent/fluent have many potential pitfalls in terms of definition and specification and that possibly a distinction should be drawn between 'fluency' as characterised in traditional terms and incorporating prosodic features such as rate, hesitations and repetitions, and between fluency in grammatical, lexical and semantic terms. If indeed there is a correlation between clinical forms of aphasia and these separate types of fluency, then the distinction is possibly worth retaining. But as the results of the present study suggest, from both terminological and conceptual viewpoints, the use of a fluent/nonfluent dichotomy in the characterisation of aphasic language probtbly warrants reconsideration.

\section{ACKNOWLEDGEMENTS}

The writer gratefully acknowledges the help and guidance of ler supervisor, Prof. M. L. Aron, Head, Dept. of Speech
Pathology and Audiology, University of the Witwatersrand. For financial assistance, the writer is indebted to the Human Sciences Research Council and to the Senate and Council Research Committees of the University of the Witwatersrand.

\section{REFERENCES}

1. Berger, H. \& Sinoff, A. Aspects of cohesion, tense and pronoun usage in the discourse of the older languageimpaired child. S.A.J. Comm. Dis., 1978, 25, 3-16.

2. Brown, C. S. \& Cullinan, W. L. Word-retrieval difficulty and disfluent speech in adult anomic speakers. $J$. Speech Hear. Res., 1981, 24, 358-365.

3. Butterworth, B. Hesitation and the production of verbal paraphasias and neologisms in jargon aphasia. Brain Lang. , 1979, 8, 133-161.

4. Cohen, J. Weighted Kappa: Nominal scale agreement with provision for scaled disagreement or partial credit. Psychol Bull. 1968, 70, 213-220.

5. Dalton, P. \& Hardcastle, W. J. Disorders of Fluency. London: Edward Arnold, 1977.

6. Deloche, G., Jean-Louis, J. \& Seron, X. Study of the temporal variables in the spontaneous speech of five aphasic patients in two situations, interview and description. Brain Lang., 1979 8, 241-250.

7. Dixon, W. J. \& Brown, M. B. MBDP. - 79 Los Angeles: U California Press, 1979.

8. Goldman-Eisler, F. Psycholinguistics London and New York: Academic Press. 1968.

9. Goodglass, H. \& Kaplan, E. The Assessment of Aphasia and Related Disorders. Philadelphia: Lea and Febiger, 1972.

10. Holland, A. L. Communicative abilities in daily living. Baltimore: University Park Press, 1980.

11. Holland, A. L. Observing functional communication of aphasic adults. J. Speech Hear Dis., 1982, 47, 50-56.

12. Kertesz, A. Aphasia and Associated Disorders. New York: Grune \& Stratton, 1979.

13. Kinsbourne, M. \& Warrington, E. U. Jargon Aphasia. Neuropsychologia, 1963, I, 27-37.

14. Morris, R., Blashfield, R. \& Satz, P. Neuropsychology and cluster analysis: Potentials and problems. J. Clinical Neuropsychology, 1981, 3, 79-99.

15. Quinting, G. Hesitation phenomena in adult aphasic and normal speech. The Hague: Mouton, 1971.

16. Wagenaar, R., Snow, C. \& Prins, R. Spontaneous speech of aphasic patients: A psycholinguistic analysis. Brain Lang, 1975, 2, 281-303.

17. Yairi, E. \& Clifton, N. F Disfluent speech behaviour of preschool children, high school senior and geriatric persons. J. Speech Hear. Res., 1972, 15, 714-719.

18. Yairi, E., Gintavitas, J. \& Avent, J. R. Disfluent speech associated with brain damage. Brain Lang, 1981, 14,
$49-56$. 


\section{Philips Hearing Aid Services}

A Division of S.A. Philips (Pty) Ltd.

\section{hearing aids Amplaid audiometers}

\section{mmm}

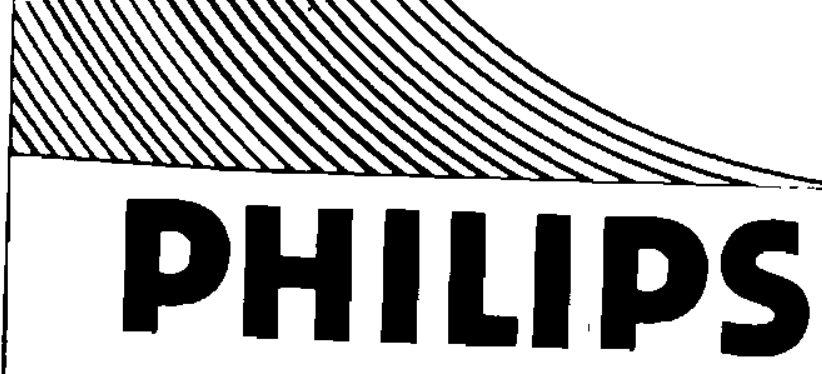

HEARING AID SERVICES

Head Office 1005 Cavendish Chambers, 183 Jeppe Street, P.O. Box 3069, JOHANNESBURG.

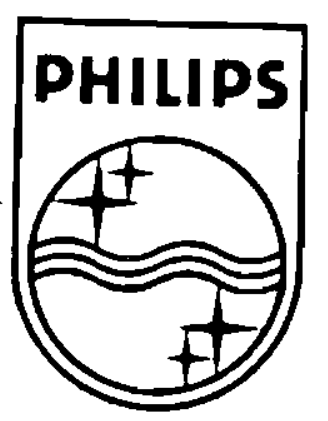

